\title{
Correlation Between Cohesive Devices Mastery and Learning Motivation Toward Reading Comprehension
}

\author{
Arining Tyas Utomo, Muh.Asrori, Hefy Sulistyawati \\ English Education Department \\ Teacher Training and Education Faculty \\ Sebelas Maret University of Surakarta
}

Email: arin.ningtyas@gmail.com

\begin{abstract}
The aims of the research are to investigate whether there is a positive correlation between (1) cohesive devices mastery and reading comprehension; (2) learning motivation and reading comprehension; (3) cohesive devices mastery, learning motivation simultaneously toward reading comprehension. The method used in this research is correlation. The study was conducted at a senior high school in Sukoharjo. The population of the research consists of 253 students. The sample is 34 students taken by cluster random sampling. The instruments in collecting the data are questionnaire and objective test. The technique of analyzing the data are simple and multiple linear regression and correlation. The result of the research shows that there is a positive correlation between (1) cohesive devices mastery and reading comprehension; (2) learning motivation and reading comprehension; (3) cohesive devices mastery, learning motivation simultaneously toward reading comprehension. Based on the research result, it can be concluded that cohesive devices mastery and learning motivation give contribution in the improvement of reading comprehension.
\end{abstract}

Keywords: cohesive devices, learning motivation, reading comprehension

\section{INTRODUCTION}

Reading is one of the essential skills in learning English as communication. The ability to read empowers the readers to take control their own knowledge. Catherine and Wallace (1994:4) say that reading as interpreting means reacting to a written text as a piece of communication. In reading process the reader interacts with the writer through understanding the information and the message in the text. Reading cannot be separated from comprehension.

Snow (2003:1) defines reading comprehension as the process of simultaneously extracting and constructing meaning. It suggests that in reading comprehension process, the reader needs to figure out how print represents words and engages the translation of the print, at the same time the reader needs to formulate a representation of the information being presented by involving his ability in building new meanings and knowledge.

Considering the theory above reading is a process in which the reader communicates with the text to extract meaning by means of his or her previous knowledge and to try to get the message of the text. Reading comprehension skills involve mentioning the main idea, identifying referent, interpreting implicit message, getting explicit message, identifying the meaning of certain word from the text.

According to Brown (2000:306-310) there are ten such strategies for reading comprehension: a) identifying the purpose in reading; b) using graphemic rules and 
patterns to aid in bottom-up decoding (beginning level learners); c) using efficient silent reading techniques for relatively rapid comprehension (for intermediate to advance levels); d) skimming the text for main ideas; e) scanning the text for specific information; f) using semantic mapping or clustering. The strategy of semantic mapping or grouping ideas into meaningful cluster helps the reader to provide some order to the chaos; $\mathrm{g}$ ) guessing when you aren't certain. Guess the meaning of a word, a grammatical relationship; h) analyzing Vocabulary. Several techniques in analyzing vocabulary, look for prefixes, suffixes, rots, etc; i) distinguishing between literal and implied meanings; j) capitalizing on discourse markers to process relationship. A clear comprehension of discourse marker can greatly enhance learners' reading proficiency.

A text consists of words, phrases, sentences and paragraphs which are arranged in a string by the cohesive devices, so it is important to master cohesive devices in order to comprehend a text. Supporting those ideas, Nuttal (1996:78) warns that poor knowledge of cohesive devices such as referring pronouns, conjunction, substitutions and ellipsis can that significantly decrease comprehension level.

According to Halliday and Hasan, there are several types of cohesion: 1) Reference, all texts have some elements that refer to something else for interpretation, i.e.: he, she, it, they, we, you, it, his, her, their, my, your, our, mine, yours, ours and its. 2) Conjunction. Conjunctions express certain meanings which presuppose the presence of other components in the discourse. There are numbers of common conjunctive elements, such as and, but, yet, so and then. 3) Substitution. It is the replacement of one item by another.
Substitution implies a repetition of a particular vocabulary item. 4) Ellipsis. It can be interpreted as that form of substitution but in this case just let the structural slot is replaced by nothing. 5) Lexical cohesion. Lexical cohesion is achieved by the selection of vocabulary, for example: People, person, man, woman, child, boy, girl (human).

Based on the discussion above, it can be concluded that cohesive devices are part of language system which creates connectivity and continuity between one parts of text. Cohesive devices mastery itself is a skill to understand signals of relation between sentence and paragraph among the text. It helps the reader to gain information that is required for interpretation.

Another factor that contributes the students' ability in comprehending text is motivation. According to Slavin (1994: 152), "Motivation is an inner drive, impulse, emotion, or desire that moves one to a particular action". It means that motivation refers to peoples' choices in doing something or not based on their.

Elliott et al (2000 332) add that motivation is an act of the students to produce a certain kind of behaviour which is maintained at a certain level of intensity and directed toward a definite goal. It arouses, sustains, directs and integrates behaviour. In line with Elliot et al, Malthy et al define,"motivation is what energizes us and directs our activity to achieve the goal" (1995: 307). Based on the definitions above, it can be concluded that motivation is an internal drive that encourage the students to produce a certain kind of behaviour in order to achieve a set of goals.

Proposed by Elliot et al (2000:338), there are several functions of motivation. First, motivation increases an individual energy and activity level. In this case, 
motivation stimulates the students to engage in lesson and learning activities intensively. Second, motivation directs an individual to gain certain goal. It affects students choices make and the result they find. Third, motivation promotes initiation of certain activities and persistence in those activities. It increases the students' effort to begin something on their own persist in the face of difficulties. Fourth, motivation affects learning strategies and cognitive process an individual employs. It stimulates the students to do their best to learn and practice learning experiences and to help for difficulties encountered.

Based on the explanation above, the writer conducted a study of the correlation between cohesive devices mastery and learning motivation and reading comprehension. The objectives of the study are to find out the correlation between (1) cohesive devices mastery and reading comprehension; (2) learning motivation and reading comprehension; (3) cohesive devices mastery and learning motivation simultaneously and reading comprehension.

The aim of this article is to explain the correlation between cohesive devices mastery, learning motivation and reading comprehension. Furthermore, this article gives information about the contribution of cohesive devices mastery and learning motivation toward reading comprehension, how much cohesive devices mastery and learning motivation support students' capability in comprehending a text.

\section{RESEARCH METHODS}

This research was carried out a senior high school in Sukoharjo. The research was conducted on the eleventhgrade students of senior high school. The sample of this research is 34 students. The method of the study used is correlational method. Correlational method is a method which aims to describe the relation between two or more events or characteristics (Hallonen and Santrock, 1999: 20). The reason of choosing this method is that this research wanted to know the level of the relation between two or more variables based on correlation coefficient.

In this research there are two kinds of variables namely independent and dependent variables. The independent variables are cohesive devices mastery and learning motivation, while the dependent variable is reading comprehension.

The writer used questionnaire and test as the techniques to collect the data of the study. According to Nunan (1992: 231) questionnaire is instrument for collecting the data, usually in written form, consisting of open and/or closed questions and other probes requiring a response from subject. In this study the writer used questionnaire to measure the data of learning motivation consisting of 40 items in the try-out and 35 items in the real questionnaire. The writer used the positive and negative items.

Besides questionnaire, another technique used to collect the data was test. Test is a method of measuring a person's ability or knowledge or performance in a given area (Brown, 2004: 3). The writer used test to measure the data of cohesive devices mastery and reading comprehension. The type of test was objective test in the form of multiple choices type. There are four alternative answers in each item, consisting one correct answer and three destructors.

The first was test of cohesive devices mastery. It was used to collect the data about the students' cohesive devices mastery. This test consisted of 45 items in the try-out and 37 items in the test which covered conjunction, reference, ellipsis, substitution 
and lexical cohesion. The second was test of reading comprehension to collect the data about the students' reading skills. The reading comprehension consisted of 50 items in the try-out and 39 items in the test which covered mentioning main idea, identifying referent, interpreting implicit message, getting explicit message and identifying the meaning of certain word from the text.

In analyzing the data, the researcher tested the three hypotheses of the study. Product Moment Formula is used to test the first and the second hypotheses. Besides, to know whether the coefficient correlation between $\mathrm{X}$ and $\mathrm{Y}$ is significant or not, the researcher uses $t$ test formula. The correlation coefficient is significant if the value of $t$ observation $\left(t_{0}\right)$ is higher than $t$ table $\left(\mathrm{t}_{\mathrm{t}}\right)$, or $\mathrm{t}_{\mathrm{o}}>\mathrm{t}_{\mathrm{t}}$.

Multiple Linear Correlation was used to test the third hypothesis which says that there is a positive correlation between cohesive devices mastery and learning motivation toward reading comprehension. Besides, to find out whether or not the coefficient of $\operatorname{Ry}(1,2)$ is significant, the researcher used $\mathrm{F}$ test formula. The correlation coefficient is significant if the value of $\mathrm{F}$ observation $\left(\mathrm{F}_{\mathrm{o}}\right)$ is higher than $\mathrm{F}$ table $\left(\mathrm{F}_{\mathrm{t}}\right)$, or $\mathrm{F}_{\mathrm{o}}>\mathrm{F}_{\mathrm{t}}$.

\section{RESEARCH FINDINGS AND DISCUSSIONS}

The data of cohesive devices mastery are collected by using objective test. The highest score of cohesive devices mastery is 84 and the lowest score is 54. The mean of the data is 68.088 and the standard deviation is 8.812 .

The data of learning motivation were collected by questionnaire. From the questionnaire it is found that the highest score is 126 and the lowest score is 106 . The mean of the data is 116 and the standard deviation of the data is 4.954

Last, the data of reading comprehension test was obtained that the highest score is 91 and the lowest score is

63. The mean of the data is 77.471 and the standard deviation is 6.436 .

The writer used Pearson Product Moment formula to test the first hypothesis. The first hypothesis says that there is a positive correlation between cohesive devices mastery $\left(\mathrm{X}_{1}\right)$ and reading comprehension $(\mathrm{Y})$. The correlation analysis shows that the correlation coefficient $\left(\mathrm{r}_{\mathrm{x} 1 \mathrm{y}}\right)$ between cohesive devices mastery $\left(\mathrm{X}_{1}\right)$ and reading comprehension (Y) is 0.916 . After being calculated to the t-value, the value of $\mathrm{t}_{\mathrm{o}}$ ( $\mathrm{t}$-obtained) is 9.523

The value of $\mathrm{t}_{\mathrm{t}}(\mathrm{t}$-table) at the level of significance $\alpha=0.05$ for $\mathrm{n}=34$ is 1.70 . Because $t_{o}(9.523)>t_{t}(1.70)$, the coefficient correlation is significant. It means that $\mathrm{H}_{\mathrm{o}}$ is rejected. So, there is a positive correlation between cohesive devices mastery $\left(\mathrm{X}_{1}\right)$ and reading comprehension $(\mathrm{Y})$. The coefficient of determination between $\mathrm{X}_{1}$ and $\mathrm{Y}$ is 0.839 . It means that $83.9 \%$ variance of reading comprehension ( $\mathrm{Y}$ ) is determined by cohesive devices mastery $\left(\mathrm{X}_{1}\right)$ and $16.1 \%$ variance is determined by other factors.

The second hypothesis in this research says that there is a positive correlation between learning motivation $\left(\mathrm{X}_{2}\right)$ and reading comprehension $(\mathrm{Y})$.. The correlation analysis shows that the correlation coefficient $\left(\mathrm{r}_{\mathrm{x} 2 \mathrm{y}}\right)$ between learning motivation $\left(\mathrm{X}_{2}\right)$ and reading comprehension ( $\mathrm{Y}$ ) is 0.708 . After being calculated to the $t$-value, the value of $t_{0}(t-$ obtained) is 5.671. The value of $t_{t}(t-t a b l e)$ at the level of significance $\alpha=0.05$ for $n=34$ is 1.70. Because $t_{0}(5.671)>t_{t}(1.70)$, the coefficient correlation is significant. It means that $H_{o}$ is rejected. So, there is a 
positive correlation between learning motivation $\left(\mathrm{X}_{2}\right)$ and reading comprehension (Y). The coefficient of determination between $\mathrm{X}_{2}$ and $\mathrm{Y}$ is 0.51 . It means that $51 \%$ variance of reading comprehension $(\mathrm{Y})$ is determined by learning motivation $\left(\mathrm{X}_{2}\right)$ and $49 \%$ variance is determined by other factors.

The third hypothesis, the researcher analyzed the collected data by using the Multiple Linear Regression Formula. This hypothesis says that there is a positive correlation between cohesive devices mastery $\left(\mathrm{X}_{1}\right)$, learning motivation $\left(\mathrm{X}_{2}\right)$ simultaneously and reading comprehension(Y). The multiple linear regression analysis shows that the coefficients of $a_{1}, a_{2}, a_{0}$ are $0.648,0.127$, and 18.538. Therefore, the multiple linear

regression equation of $\mathrm{Y}$ on $\mathrm{X}_{1}$ and $\mathrm{X}_{2}$ becomes $\hat{Y}=18.538+0.648 \mathrm{X}_{1}+0.127 \mathrm{X}_{2}$. The multiple correlation analysis shows that the correlation coefficient Ro is 0.918. The value of $F_{o}$ is 84.086 and the distribution table $\left(\mathrm{F}_{\mathrm{t}(2.31)}\right) \alpha=0.05$ is 2.92 . It is obvious that $\mathrm{F}_{\mathrm{o}}>\mathrm{F}_{\mathrm{t}}$; it means that the regression of $\mathrm{X}_{1}, \mathrm{X}_{2}$, and $\mathrm{Y}$ is significant.

Because $F_{o}(6.266)>F_{t}(3.467)$, the coefficient correlation is significant. It means that $\mathrm{H}_{\mathrm{o}}$ is rejected. So, there is a positive correlation between cohesive devices mastery $\left(\mathrm{X}_{1}\right)$ and learning motivation $\left(\mathrm{X}_{2}\right)$ simultaneously and reading comprehension $(\mathrm{Y}) \cdot \mathrm{R}^{2}(0.844)$ is coefficient of determination. It means that $84.4 \%$ variance of $\mathrm{Y}$ is determined by $\mathrm{X}_{1}$ and $\mathrm{X}_{2}$ and $15.6 \%$ variance of $\mathrm{Y}$ is determined by other factors.

The result of the correlation analysis between two independent variables and one dependent variable is a positive and significant. The correlation between cohesive devices mastery, learning motivation, and reading comprehension can be illustrated as follows.
There is a positive correlation between cohesive devices mastery and reading comprehension. It means that cohesive devices mastery supports reading comprehension activity. In other words, the improvement of cohesive devices mastery is followed by the improvement of reading comprehension.

Reading comprehension activity is not only knowing the meaning of each word but also comprehending the message of the text. There are some competences which facilitate reading comprehension, one of them is discourse competence. Gascoigne (2005:1) said that discourse competence is the ability to understand the cohesive devices to link meaning within and across the sentences. A writer uses cohesive devices within a text to unify the message of the text and gives a clue for the reader to understand the message of the text. Readers need to react to the signals and interprets them, so they can comprehend the text well.

Steffensen in Sukamto (2007:41) stated that teaching cohesive devices can help the students in increasing their capability of understanding the meaning of the passage. It means that cohesive devices mastery is very helpful in students comprehending a text. Without cohesive devices mastery, students will get hard time to understand the meaning and the relation of each sentence or paragraph of the text.

From the explanation above, it can be concluded that cohesive devices mastery is needed to help reader in understanding the relation between the sentences to get the unity message of the text. Besides, cohesive devices mastery can be determined as the factor in reading comprehension activity. It means that, if students have good cohesive devices mastery they will comprehend the passage well. 
Second, there is a positive correlation between learning motivation and reading comprehension indicates that learning motivation contributes toward reading comprehension. The increase of learning motivation will be followed by reading comprehension.

Reading will be fun and interesting if there is intrinsic factor affecting them, such as motivation. Motivation is needed in order to encourage the reader in reading activity. Motivation can be included into the factor in reading comprehension activity. Students with high motivation will get better achievement in reading comprehension than the others with low learning motivation.

Baker and Wigfield (1999:1) said, "reading is an effortful activity when children often can choose to do or not to do, it also requires motivation". It means that reading is not only supported by cognitive aspects. Students' motivation also takes important role in reading activity. Students with high motivation will more engage in reading. They will put more effort in reading activity to gain their purpose. Students with high motivation will more engage in reading. They will put more effort in reading activity to gain their purpose.

Last, there is a positive correlation between cohesive devices mastery and learning motivation simultaneously and reading comprehension means that cohesive devices mastery and learning motivation supports reading comprehension. the improvement of Cohesive Devices Mastery and learning motivation were followed by reading comprehension.

Based on the previous explanation, there are two factors affecting reading comprehension: cohesive devices mastery and learning motivation. Reading is a complex activity which requires reader's background knowledge and the information suggested by the writer to construct the meaning of the text. To acquire reading comprehension skill knowing the meaning of each word is not enough for the students. Another aspect contributing to reading comprehension is cohesive devices mastery. Students also need cohesive devices mastery to help them understand the relation each sentence in the text and get the unity passage of the text. Chapman in Sukamto (2007: 41) stated that mastery of textual features including cohesive ties is a central factor in fluent reading comprehension. It can be said that cohesive devices mastery has important role in reading comprehension. It helps students to construct the meaning of the text by understanding the ties between sentences and paragraph in the text. The better students' cohesive devices mastery, the better the students achieve reading comprehension.

Supporting the cohesive devices mastery, internal factor also has important role in reading comprehension. Motivation is an internal factor that makes someone decide to do or not to do something. Slavin (2009: 297) stated that motivation is important not only in getting students to engage in academic activities but also how much students will learn from the activities they perform or from information to which they exposed. Motivation can be seen from their effort and their willing in doing something. High motivated students or low motivated students can be easily known by their effort and willingness in doing activities during teaching learning process.

From the explanation above, it can be said that the result of the research is suitable to the theoretical discussion. Cohesive devices mastery and learning motivation simultaneously support reading comprehension. Therefore, it can be pointed 
out that cohesive devices mastery and learning motivation can be classified as the determinant factors in reading comprehension

\section{CONCLUSIONS AND SUGGESTIONS}

From the hypotheses testing, it can be concluded that there is a positive correlation between cohesive devices mastery and reading comprehension, learning motivation and reading comprehension, and cohesive devices mastery and learning motivation simultaneously and reading comprehension.

Based on the research finding, it can be explained that cohesive devices mastery, learning motivation give contribution to reading comprehension. The implication of the study is that the teacher should improve the students' cohesive devices mastery and should maintain students' learning motivation, in order that the students' reading comprehension can improve too.

Teacher should create learning process situation which can increase students' learning motivation. There are many students' characteristics in the class. Teacher should give more attention to the students' characteristic diversity, so the teacher is able to create variation in teaching learning purpose in order to fulfill the students' need with different characters in learning process actively. Teacher should find way to keep students' motivation. It will be useful for students to maintain their motivation in learning, because the higher their motivation, the better their learning achievement.

Considering that mastery cohesive devices is crucial in reading comprehension, teachers should include classroom instruction on the cohesive devices, and their function across sentences and paragraphs. Teachers give exercises which aimed to improve students' ability in recognizing cohesive devices in written discourse which is expected to improve their reading comprehension. For example, the students are asked to recognize cohesive devices mastery in the text by investigating the connection between the sentences such as looking for reference then classifying and mentioning the function. Filling gaps test is also needed in order to improve the students' ability in using cohesive devices. Cohesive devices mastery helps the reader to understanding the unity of the text, so they can comprehend well the meaning and the message of the text.

From the explanation before, it can be concluded that cohesive devices mastery and learning motivation give contribution in reading comprehension activity. They can be classified as the determinant factors in reading comprehension. The improvement of cohesive devices mastery and learning motivation are followed by the increase of reading comprehension skill.

With regard to the implication above, the writer proposes the following suggestions: (1) the teachers should be aware that there are many factors influencing reading comprehension such as cohesive devices mastery and learning motivation simultaneously (2) the teacher should give a close attention to the teaching learning material, learning environment and students' diversity characteristics in order to develop their learning motivation (3) teacher should be aware of the importance of cohesive devices mastery in reading comprehension activity. Teacher could give exercises to improve students' ability in recognizing cohesive devices in a text.

For the students, the researcher suggests as follows: (1) The students should be aware that cohesive devices mastery and learning motivation are important factors in 
reading comprehension activity. (2) The students should improve their cohesive devices mastery which is giving contribution in reading comprehension activity. (3) The students should keep and develop their motivation because it will help them in achieve better reading comprehension skill.

For other researchers, the writer realizes that the result of this research still has many lacks, but the writer expects that this research will be useful as a reference to their researches. Besides, this research can also be used to carry out a similar study. Many other aspects, besides cohesive devices mastery and learning motivation could influence reading comprehension and other language skills. Other researchers who are willing to conduct the same kind of the research, are suggested to investigate other factors to accomplish the list internal and external factors which influence reading comprehension in particular or the other language skills which are not investigated in this study.

\section{BIBLIOGRAPHY}

Baker, Linda and Allan W. Dimensions of Children's Motivation and Their Relation to Reading Activity and reading Achievement. 1999. Reading research Quarterly, 34,452-477.

Brown, H. Douglas. 2000. Teaching by Principles an Interactive Approach to Language Pedagogy Second Edition. San Francisco: Longman

Brown, H. Douglas. 2004. Language Assessment: Principles and Classroom Practice. San Francisco: Longman.
Elliot, Stephen. N. et.al 2000. Educational Pshychology; Effective Learning. Madison: Brown and Benchmark Publisher.

Gascoine, Carolyn. 2005. Toward and understanding of the relationship between L2 reading comprehension and grammatical competence. The Reading Matrix, 5, 1-14.

Halliday, M., and Hasan, R., 1976. Cohesion in English. London. Longman.

Hallonen, Jane S and Santrock, John W. 1999. Psychology: Applied and Application $3 r d$. New York: Mc Graw-Hill College.

Malthy et.al. 1995. Educational Psychology, An Australian and New Zealand Perspective. Singapore: John Willey and Son.

Nunan, David. 1998. Research Methods in Language Learning. Cambridge: Cambridge Univeristy Press.

Nuttal, C. (1996). Teaching Reading Skills in a Foreign Language. Oxford: McMilla Heinmann.

Slavin, Robert E. 1997. Educational Psychology; Theory and Practice. Boston: Allyn and Bacon.

Snow, Catherine E. 2002. Reading for Understanding: toward an $R \& D$ program in reading comprehension. New York: Rand Corporation.

Sukamto, Stephanus. Cohesive Devices Recognition Skills-Building Exercises. 2007. Celt. Vol 7, No. 1, p 37-50.

Wallace, C. 1996. Reading. Oxford: Oxford University Press 